\title{
New enterant in the class of uropathogens-Shewanella algae
}

\author{
Ostwal K, Shah P, Pathak S, Jadhav A, Shaikh N \\ Department of Microbiology, Dr. Vaishampayan Memorial Government Medical College, Solapur - 413003, Maharashtra, India
}

\section{A B S T R A C T}

S. algae is considered a rare opportunistic pathogen for humans, frequently involving immunecompromised hosts and are usually part of a polymicrobial infection which may mask its clinical importance. We are reporting first ever case report of urinary tract infection caused by Shewanella algae. This is a case of 70 year old diabetic male presented with fever, urgency of micturition, oliguria, swelling over both legs. His midstream urine sample was sent for microbiological examination and it revealed Shewanella algae. Patient was treated with antibiotics and he recovered completely after treatment. This case highlights the need to consider Shewanella as a potential emerging uropathogen, and utmost microbiological vigilance is required to identify this unusual agent of UTI.

Key words: Diabetic, Shewanella algae, Uropathogen

\section{INTRODUCTION}

In 1985, MacDonell and Colwell proposed the new genus Shewanella, which was initially composed of three species: S. putrefaciens, $S$. hanedai and $S$. benthica. ${ }^{1}$ Currently, there are at least 22 species in genus Shewanella. Most of them are associated with aquatic and marine habitat. ${ }^{2}$ In 1990, Simidu et al. proposed the name $S$. algae for a tetrodotoxinproducing isolate recovered from red algae. ${ }^{3}$ Previously, Shewanella algae was known as Alteromonas putrefaciens or Achromobacter putrefaciens. ${ }^{4}$ Shewanella spp. has been implicated in skin and soft tissue infections, bacteraemia, biliary tract infections, thoracic empyema, endocarditis, dacryocystitis, intracranial abscess, arthritis, peritonitis, ventilator-associated pneumonia, and ear infections. ${ }^{5}$ In Denmark, 67 ear infections caused by $S$. algae have been published. ${ }^{6}$ We have not come across any case of urinary tract infection caused by $S$. algae.

Two Shewanella species, S. algae and $S$. putrefaciens, have been found in clinical specimens. Because automated systems are unable to distinguish between two species, a number of infections attributed to $S$. putrefaciens probably correspond to $S$. algae. ${ }^{7}$. algae is considered a rare opportunistic pathogen for humans, frequently involving immune-compromised hosts and are usually part of a polymicrobial infection which may mask its clinical importance. We are reporting first ever case report of urinary tract infection caused by Shewanella algae.

\section{CASE REPORT}

A 70 year old diabetic male was admitted in the Department of Medicine with complaints of fever since 15 days, urgency of micturition, oliguria, swelling over both legs since 4-5 months. He had a past history of being operated for $7 \mathrm{~mm}$ left renal stones 3 years back. Since then he was having recurrent episodes of urinary tract infections.

\section{Microbiological examination}

A $5 \mathrm{ml}$ clean-catch midstream urine sample was collected and was sent to the department of Microbiology for examination.

On Macroscopic examination, it was yellow and turbid urine sample. The sample was inoculated on Cysteine Lactose Electrolyte Deficient (CLED) agar by semi quantitative method and kept for incubation at $37^{\circ} \mathrm{C}$ for $16-18$ hours. 
Microscopic examination showed 10-15 Polymorphonuclear cells/hpf (PMNs) and motile bacilli. On Gram staining there was evidence of Gram negative bacilli and PMNs.

The next day a significant count of $10^{5}$ Colony Forming Unit (CFU)/ $\mathrm{ml}$ of mono-microbialnon lactose fermenting colony was found on CLED agar. ${ }^{8}$ The colony was subjected to catalase test, oxidase test and standard biochemical tests were applied. Antibiotic susceptibility testing was done by Kirby-Bauer disc diffusion method using discs of standard concentrations provided by $\mathrm{Hi}$ - media laboratory (Mumbai, India). Minimum Inhibitory Concentration (MIC) was determined by agar dilution method for ampicillin and ceftriaxone.

\section{RESULTS}

Catalase and Oxidase were produced.

\section{Biochemical reactions - (from right to left)}

TSI-alkali/acid with H2S. Indole was not produced. Methyl red and VogesProskauer test were negative. Citrate was utilised. Urease was not produced (Figure 1).

\section{Antibiotic susceptibility pattern}

It was found to be sensitive to gentamycin $(18 \mathrm{~mm})$, ciprofloxacin $(27 \mathrm{~mm})$, amikacin $(23 \mathrm{~mm})$, cefepime $(21 \mathrm{~mm})$, meropenem(32mm), ceftazidime $(28 \mathrm{~mm})$, ceftriaxone $(30 \mathrm{~mm})$, aztreonam $(26 \mathrm{~mm})$, norfloxacin $(24 \mathrm{~mm})$, nitrofluorantoin $(27 \mathrm{~mm})$ and was resistant to ampicillin $(6 \mathrm{~mm})$ and cephalothin $(6 \mathrm{~mm}){ }^{9}$

MIC was done by agar dilution and it was found resistant to ampicillin (MIC $\geq 32 \mu \mathrm{g} / \mathrm{ml}$ ) and sensitive to ceftriaxone $(\mathrm{MIC} \leq 1 \mu \mathrm{g} / \mathrm{ml})$

As Shewanella spp is only non lactose fermenting, oxidase producing organism giving $\mathrm{H}_{2} \mathrm{~S}$ on TSI it was subjected to further examination for identification of species. It was inoculated on Blood agar and MacConkey agar for confirmation.

Table 1: Biochemical tests done for Species
level identification of S. algae

On blood agar-1-2 mm, circular, convex, smooth, betahaemolytic colonies, with orange tan pigment were seen (Figure 2).

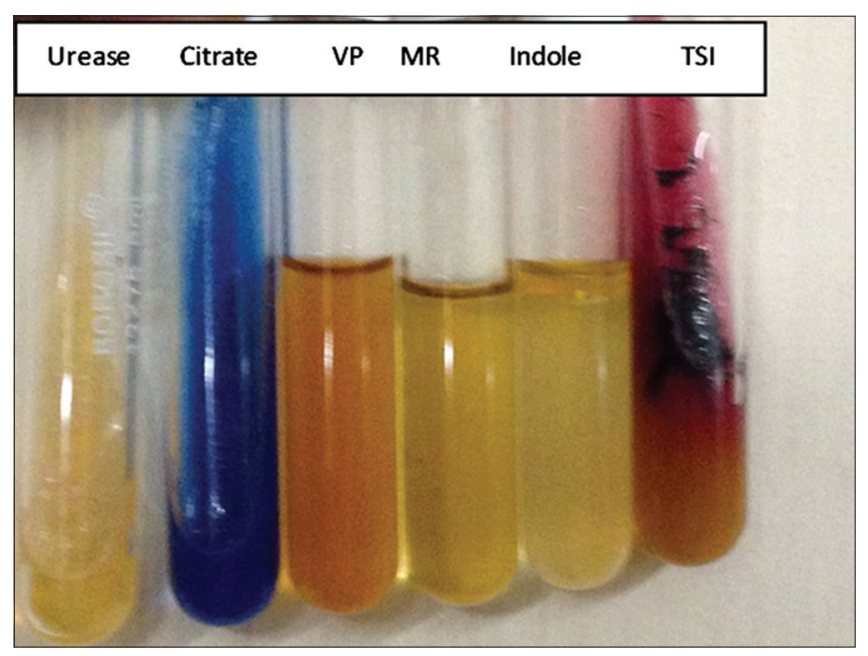

Figure 1: Biochemical properties of Shewanella algae

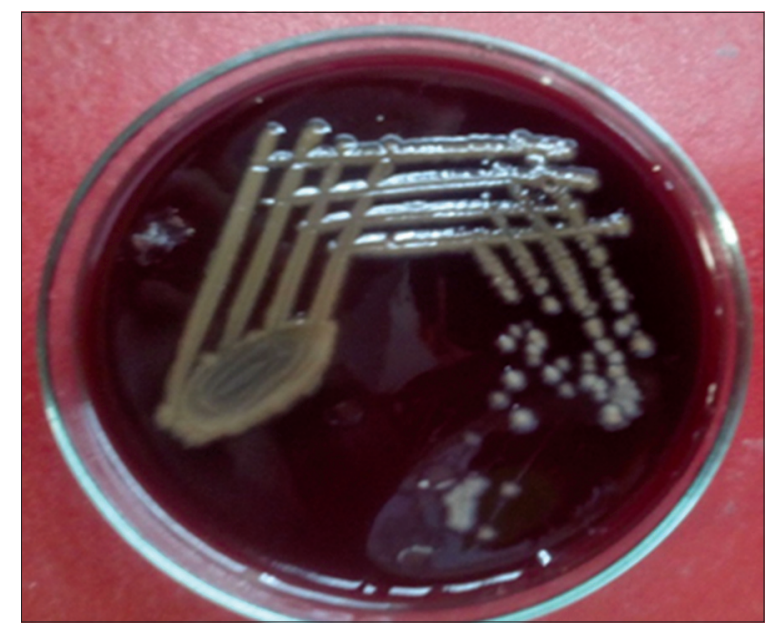

Figure 2: Colonies on blood agar. ${ }^{4}$

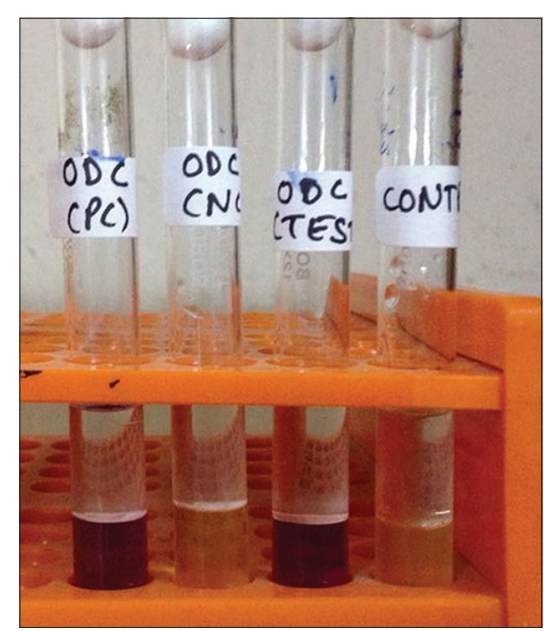

Figure 3: Ornithine decarboxylation. 
The isolate was thermo-tolerant with presence of growth at $42^{\circ} \mathrm{C}$ and halophilic with growth in presence of $6.5 \% \mathrm{NaCl}$.

The biochemical tests done for speciation of Shewanella algae are as mentioned in Table 1.

Urine biochemistry examination-

Sugar-trace, albumin-2+.

Blood investigations in biochemistry-

Blood sugar - Post prandial was $208 \mathrm{mg} \%$ and fasting was $138 \mathrm{mg} \%$,

Serum creatinine was 1.6.

Pathological examination-Haemoglobin was $11.2 \mathrm{gm} \%$, White Blood Count $-10,700 / \mathrm{cmm}$.

Differential Leucocyte Count- Neutrophils-72\%, lymphocytes- $25 \%$, monocytes- $1 \%$, basophils- 0 , eosinophils $2 \%$, Erythrocyte Sedimentation Rate $-42 \mathrm{~mm} / 1$, C-Reactive Protein $-23 m g / 1$.

\section{DISCUSSION}

Shewanella species are found throughout the world in marine environments and most reported human infections occur in countries with warm climates. ${ }^{2}$

Shewanella algae and Shewanella putrefaciens are the two species of Shewanella that are most frequently implicated in human infections. Among Shewanella spp. S. algae causes $80 \%$ human infections. ${ }^{10}$

S. algae grows at $42^{\circ} \mathrm{C}$ and in presence of $6.5 \% \mathrm{NaCl}$ and this helps to distinguish it from $S$. putrefaciens. ${ }^{4}$ Alishewanella is also halophilic but it is non motile and doesnot produce $\mathrm{H} 2 \mathrm{~S}$ unlike $S$. algae. ${ }^{4}$ The isolate can be further confirmed to the species level by $16 \mathrm{~S}$ ribosomal DNA sequencing by using the primers B27F (5'-AGAGT'TTGATCCTGGCTCAG-3') and U1492R (5'-GGT'TACCT'TGT'TACGACT'T-3') but was not done in our case. ${ }^{11}$

Patient was admitted for urinary complaints so the organism is most likely to be a community acquired rather than hospital associated pathogen. Patient was treated as a case of recurrent UTI but the clinical signs and raised albumin level with history of diabetes suggest of some pathology like diabetic nephropathy but further investigations like renal ultrasound was not done in this case so we are not sure of any long standing illness in our case. The organism generally resides in marine and aquatic environment so the route of transmission in this case is not known. There have been only four reports of isolation of Shewanella from India and these were from patients with infective endocarditis, peritonitis, and chronic obstructive pulmonary disease respectively. ${ }^{12,13}$ Shewanella was isolated in monomicrobialform with a significant bacterial count and clinical picture suggestive of acute urinary tract infection. Patient was treated with a five days course of Norfloxacin $400 \mathrm{mg}$ twice daily. Patient was improving clinically and his symptoms were relieved. A repeat sample was taken on seventh day was sterile. So we believe that Shewanella algae was the causative agent in our case.

There are no standard guidelines for treatment of Shewanella infection. In present study $S$. algae was found to be susceptible togentamycin, norfloxacin, amikacin, cefepime, meropenem, ceftazidime, cefotaxime, aztreonam, nitrofurantoin and resistant to ampicillin and cephalothin. According to some textbooks resistance is found to ampicillin and cephalothin. ${ }^{4}$ Previously published studies reported that $S$. algae is susceptible to aminoglycosides, carbapenems, erythromycin, and quinolones, with variable susceptibility to penicillin and cephalosporins. S. algae is characteristically susceptible to aminoglycosides, carbapenems, erythromycin and quinolones, but resistant to penicillin. Susceptibility to ampicillin and cephalosporins is variable, with more isolates being susceptible to third- and fourth- than to first- and second-generation cephalosporins. ${ }^{14}$ However, rapid development of resistance to imipenem and piperacillintazobactamhas been reported. ${ }^{14}$

To conclude, this case highlights the need to consider Shewanella as a potential emerging uropathogen, and utmost microbiological vigilance is required to identify this unusual agent of UTI.

\section{REFERENCES}

1. Mac Donell MT and Colwell RR. Phylogeny of the Vibrionaecae and recommendation for two new genera, Listonella and Shewanella. Syst Appl Microbiol1985; 6:171-182.

2. Goyal R, Kaur N and Thakur R. Human soft tissue infection by the emerging pathogen Shewanella algae. J Infect Dev Ctries 2011; 5(4):310-312.

3. Simidu U, Kita-Tsukamoto U, Yasumoto T and Yotsu M. Taxonomy of four marine bacterial strains that produce tetrodotoxin. Int J Syst Bacteriol 1990; 40: 331-336.

4. Winn WC, Allen SD, Janda WM, Koneman EW, Precop GW and Schreckenberger PC. Koneman's color atlas and textbook of diagnostic microbiology. Chap 7.6e. Lippincott; 2006. 303.

5. Collier L, Balows A and Susman M. Bacterial meningitis. In: Topley and Wilson's Microbiology and Microbial infections. Chap 17, 9e. Great Britain. 1998; (3):299-306.

6. Holt HM, Søgaard P and Gahrn-Hansen B. Ear infections with Shewanella alga. A bacteriologic, clinical and epidemiologic study of 67 cases. Clin Microbiol Infect 1997; 3: 329-334.

7. Nozue H, Hayashi T, Hashimoto $Y$, Ezaki T, Hamasaki K, Ohwada K, et al. Isolation and characterization of Shewanella algae from human clinical specimens and emendation of the description of S. algae.1990, 335. Int J Syst Bacteriol 1992; 
42:628-634.

8. Cheesbrough M. District Laboratory Practices in Tropical countries. Part- 2. Chap-7.2 e. New Delhi. Cambridge University Press. 2006. 51.

9. Clinical and Laboratory standards Institiute. M100-S23. Performance Standards for Antimicrobial susceptibility Testing Twenty-Third Informational supplement; Pennsylvania. 2013.

10. Khashe $\mathrm{S}$ and Michael JJ. Biochemical and Pathogenic Properties of Shewanella alga and Shewanella putrefaciens. J Clin Microbiol1998; 36(3): 783-787.

11. Po-Yu Liu, Zhi-Yuan Shi, Ching-Lin Shyu, Zong-Yen Wu, KuoLung Lai, Chih-Yen Chang, et al. Cobra bite wound infection caused by Shewanella algae. International journal of infectious diseases.ijid.2013.8.14.

12. Dhawan B, Chaudhry R, Mishra BM and Agarwal R. Isolation of Shewanella putrefaciens from a Rheumatic Heart Disease Patient with Infective Endocarditis. J Clin Microbiol 1998; 36: 2394. 6.

13. Mukhopadhay C, Chawla K, Sharma Y and Bairy I. First report of Shewanella algae as emerging infection in India: Two cases. J Clin and Diag Res 2007; 1: 293-295.

14. Holt HM, Gahrn-Hansen B and Bruun B. Shewanella algae and Shewanella putrefaciens: Clinical and microbiological characteristics. Clinical Microbiology and Infection 2005; 11(5):347-352.

\footnotetext{
Authors Contribution:

OK - Isolation of Pathogen, guidance in identification, revised the manuscript; PS, SP \& AJ - history taking, performed Lab tests, drafted the manuscript;

SN - Reviewed \& finalised the manuscript.

Source of Support: Nil, Conflict of Interest: None declared.
} 